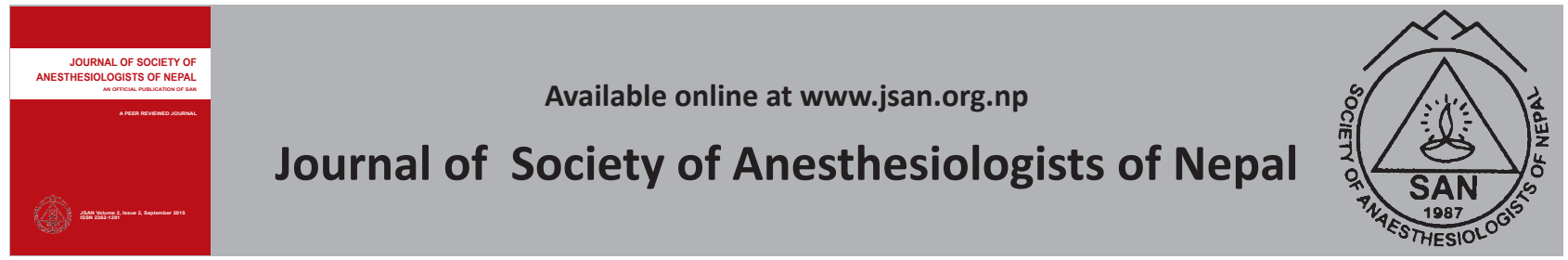

Editorial

\title{
Earthquake Disaster and Anesthesiologists' service in Nepal
}

\author{
Bishwas Pradhan, MD, FCTA
}

Editor in chief, JSAN

\begin{abstract}
Associate Professor and Chief, Cardiothoracic \& Vascular Anesthesia Unit
Manmohan Cardiothoracic Vascular \& Transplant Centre

Tribhuvan University, Institute of Medicine, Maharajgjunj Medical Campus,

Maharajgunj, Kathmandu, Nepal
\end{abstract}

At midday on April $25^{\text {th }} 2015$, an earthquake of magnitude 7.8 on the Richter scale struck Nepal. The epicentre was in the mountainous village of Barpak near Kathmandu. The lack of forewarning and the nearly one minute of incredible shaking were terrifying for everyone. Approximately 9000 people were killed and 23,000 were injured. Homes, schools, hospitals, businesses and national heritage sites, including temples and monasteries, were extensively damaged or destroyed. Healthcare facilities in remote areas near the epicentre were devastated and completely unable to function at the time they were most needed.

Just when families were in greatest need of practical and moral support, professionals with duties in police, military and health care had to be away from their families doing their jobs. National and civic leaders, transportation workers, media personnel and volunteers also sacrificed family time and attended energetically to duties.

Major hospitals in the Kathmandu Valley provided service to patients from within the Valley and to hundreds more arriving from other areas where health care facilities were non-existent or destroyed. Many international organizations and medical teams arrived to assist relief and rescue operations. While the international support was needed and appreciated, the majority of patients in Valley hospitals were treated by Nepalese physicians. As expected, anesthesiologists as well as surgeons from the disciplines of trauma, orthopedics, neurosurgery and plastic surgery worked the longest days and nights during the acute crisis. Other physicians were also busy with triage and management of complications including infection, renal failure and the psychological stresses of the disaster.

The service of Nepal's anesthesiologists during the earthquake and its aftermath deserves some spotlight. Anesthesia has a short history in Nepal, with the first anesthesiologist beginning service in 1955. Before then, and for many years after, anesthesia service could be provided by any experienced medical nor non-medical personnel who could pour chloroform or ether in the mask used to cover the external airways of the patient. Gradually, more Nepalese anesthesiologists were trained in the United Kingdom. In the 1980's, a one year Diploma Program in Anesthesia began in Kathmandu and in the 1990's a three year MD program was established. The MD program now operates in nine institutions. These programs have been great leaps forward in provision of anesthesia care in Nepal. Few anesthesiologists are still trained outside the country.

The earthquake tested the capacity of anesthesia services in the country. All hospitals left structurally intact after the quake which required anesthesia service to manage victims, received this service without interruption throughout the country. Though the volunteer foreign medical teams helped, no hospital had to refer victims elsewhere due to lack of anesthesia services provided by Nepalese anesthesiologists.

Roles for anesthesiologists during the disaster included disaster command centre leadership in hospitals; triage of patients and resources to maximize efficient care delivery; acute resuscitation and stabilization before surgery; intraoperative anesthetic care; critical care; and management of acute and chronic post-traumatic and postoperative pain.

The disaster was a learning experience for all anesthesia personnel. Makeshift operating rooms were organized in shipping containers and under hastily constructed tin roofs too. Teams of divergent background set differences aside, worked long hours, and made due with inadequate supplies of anesthetic medications and equipment.

In reflection, Nepalese anesthesiologists and their support staff must be proud of their contribution to managing a natural disaster of epic international proportion. 
Challenges imagined but hoped never to be faced, were met and managed. Lives and limbs were saved.

This editorial recognizes and thanks all of the Nepalese and international anesthesiologists who contributed to the development of anesthesia education and service in Nepal; all anesthesia personnel - staff, medical officers, anesthesia assistants and non-medical supporters - who managed the disaster; and all of their families who had to make do in the face of professional duties.

I dedicate my article to all the national and international senior anesthesiologists who planned and worked to develop anesthesia service to this scale from scratch and all the anesthesiologist colleagues, residents, medical officers, anesthesia assistant and other medical and nonmedical staffs who made us successful in tackling the national crisis of this magnitude. 